\title{
Being Negative to be Popular: Style in Online Comments at the Mail Online
}

\author{
Sean Sutherland* \\ United Kingdom \\ *Corresponding Authors: Sean Sutherland, United Kingdom
}

\begin{abstract}
Language users may make stylistic choices to signal group membership (Rampton 2002). The use of an aggregate of common linguistic features that are distinct from those of other groups of language users can be a sign of shared values in a linguistic 'community of practice' (Eckert and McConnell-Ginet 1992). New members of such a community display their knowledge of the group's practices, and thus their desire to be accepted as members of the community, by mimicking the language of more established members. The purpose of this research is to uncover stylistic features of a relatively new genre of text, online newspaper comments. This research argues that comments posted by readers of online newspapers provide us with the opportunity to both identify some shared stylistic features of a community of practice and to see how other readers evaluate the use of those features by deciding whether or not to approve or disapprove of the comments made. The top-rated comments from Mail Online newspaper articles with more than one thousand comments were collected over a period of one week, leading to a dataset of 65 comments that were analysed qualitatively using discourse analytic tools. The high number of approving votes for these comments suggests that other readers approve of their content and stylistic delivery. Previous studies (Anderson et al. 2014; Blom et al. 2014; Reagle 2015; Santana 2011) have suggested that online comments tend to be negative, but have said little about how the comments are realised or why there is a tendency to be negative. Based on the results of this analysis I argue that, through the use of common language choices (similar grammatical structures, little or no epistemic modality, implicature), commentators aim to accrue upvotes to validate themselves as core members of the Mail Online commentator community of practice.
\end{abstract}

Keywords: style; discourse; online; comments; newspaper

\section{INTRODUCTION}

This research aims to describe the most common stylistic features in online comments on news articles in the Mail Online, the online version of the United Kingdom-based Daily Mail newspaper. Stylistic analysis investigates how linguistic choices are made by language users and the effects that those choices have on language receivers (Coupland 2007). With regards to media stylistics in particular, as Lambrou and Durant (2014) argue, the aims are to analyse samples of genres of text in order to describe their generic features; discuss any relevant extra-linguistic, cultural or political factors; then assess the potential effect of those features on readers. In this research, it is argued that most-highly-rated comments tend to feature either a direct carrier + relational process + attribute structure (Halliday and Matthiessen2014) or use implicature (Grice 1975) to present their messages indirectly. Comments mostly appeared without modality or appeared with high epistemic modality denoting certainty (Palmer 2001), which suggests that commentators who present themselves as confident are more likely to accrue 'upvotes', a sign of a comment's success with other readers. Stylistic choices can be used to signal an awareness of a particular community's linguistic practices and membership in that group (Rampton 2002). It is argued here that commentators at the Mail Online use these stylistic conventions when posting in order to accumulate upvotes, a quantifiable sign of acceptance by the Mail Online 'community of practice' (Lave and Wenger 1991).

The Mail Online is of particular significance as a site of analysis due to its popularity, with some metrics showing it to be the United Kingdom's most visited national newspaper website (Fothergill 2014). Reich (2011) explains that only a small fraction of those who visit online news websites post comments, but the Mail Online's size is such that there are sometimes hundreds of individual comments on particularly popular articles, and many more site users, sometimes over ten thousand, 
participate in the comment process by 'upvoting' or 'downvoting' comments to show their approval or disapproval of what has been written. Reagle (2015) argues that the popularity of posting comments is such that they help set the news agenda, with news outlets perhaps favouring those topics that are likely to see high numbers of comments and votes. Such articles about controversial topics designed to promote commentary lead to increase readership and thus increased advertising revenue. Unlike some comment systems, the Mail Online makes 'downvotes', that is, registers of disapproval, viewable to site users. Online comments at the website thus give analysts the opportunity to see what some site users write in reaction to the daily news, and to make some informed analysis about which stylistic features may make some comments popular or not with the sample of the readership population that chooses to vote on those comments.

\section{LITERATURE REVIEW}

For linguists, educators and others with an interest in language use, the increasing popularity of online commentary has provided the relatively rare opportunity to examine a new genre of text as it develops. Swales (1990) defines a 'genre' as a group of communicative events that share a purpose. Members of a genre may "vary in their prototypicality" (p49) but have expected structures that allow them to be identified as genre members. Unlike those genres that are "clear-cut... political speeches, lectures, post-match sports interviews" (Coupland 2007 p15), online commentary content does not always have clearly-defined generic conventions, and assumed similarities between comments on different web-based and social media platforms may not exist. Tagg et al. (2017) explain, for example, that while giving and taking offense is frequent on Facebook, users of that social networking site also seemed to work towards establishing a convivial relationship with other Facebook users through their posts, unlike on Twitter or in online news commentary (Rowe 2015), which is more adversarial.

Online comments provide analysts with the opportunity to watch written mode, multi-author texts develop throughout the course of a news article's duration of relevance. Commentators can quickly author largely unfiltered, publicly-viewable reactions to the news articles below which their comments will appear when posted. Some news organisations employ moderators, staff that remove comments for various reasons, but the Mail Online's comment sections usually begin with the announcement that "The comments below have not been moderated", which suggests that analysts of language are seeing naturally-occurring discourse when they examine online comments. I use 'text' to mean 'words and / or symbols that present a coherent message' (Halliday and Hasan 1976), and 'discourse' to mean 'the text and the temporal and physical content in which it exists' (Georgakopoulou and Goutsos 1997). Individual comments are written texts, but their co-occurrence with other comments and with the article being commented leads to their interpretation by readers as part of an on-going discourse.

Online comments of the type discussed in this research are typically organised in multiple layers. First-order comments react to the news article below which the comments appear. Second-order comments, typically indented, reduced in size, or otherwise marked as such, appear sequentially in order of posting below the first-order comments to which they react. (First-order commentators and first-order comments are often referred to by other commentators as 'OP', meaning 'original poster' or 'original post'.) A first-order comment and related second-order comments are often called 'threads'. As is common in many comment systems, users of the Mail Online's can sort first-order comments chronologically from first to last or vice-versa, or in terms of popularity or lack thereof: 'Newest', 'Oldest', 'Best rated', and 'Worst rated'. The second-order comments are embedded with the first-order comment which they react to, so any sorting moves them together. Second-order comments cannot be sorted independently and so appear only in the chronological order of posting. Reagle (2015 p96) has identified as four generic features of comments. First, they are 'communication' produced to be read by other users, which we can surmise to be true from the upvotes and downvotes. Second, they are 'reactive' in that their content is related to the articles they appear with. Third, they are 'short', a vague term, but reasonable enough if we compare a comment to the article that it appears below. Fourth, they are 'asynchronous', for there is no set time between the appearance of one comment and the next one that may follow it, and there is no allowance for overlap in production, unlike in a multi-party spoken conversation.

Reagle's description provides information about the mode of production of the comments, but little about the stylistic choices commentators make, other than the fact that brevity is typical. However, the 
starting point for discussion about comments, both in popular discourse and academic discourse, is not their length, but the oft-justified poor reputation they have for being negative. For example, The Guardian newspaper's research into its own comment sections found that such comments were often "just vile" (Gardiner et al 2016).

The term 'negative' is used in this research to mean "critical, unfavourable, carping; hostile, destructive, antagonistic" (OED Online 2018). Reagle's (2015) introductory description of online comments summarises them as "weak to poor", "pure trollish nonsense", "the [metaphorical and literal] bottom half of the web", "obsessively vitriolic" and "hateful and misogynist". Online comments often feature attacks on others' 'positive face' (Brown \& Levinson 1987), the desire people have to be addressed positively, thought well of, and so on, that would be unthinkably rude is all but the most argumentative or abusive face-to-face interactions.

Wright and Street (2007) write that most criticism of online comments blames the negative perception of such on the immediacy of response that posting allows, that same spontaneity that makes comments sections similar in many ways to unplanned conversations. Comment writers do not need to contemplate their choice of words as they compose a letter, find a stamp, and so on. While the majority of conversations are held face-to-face, often with interlocutors that one knows, comment discourse is anonymous, a feature that Santana (2011) argues is the prime cause of the negative, inflammatory comments that are associated with online comments. (I make no distinction between 'anonymity', in which no name is seen, and 'pseudonymity', in which the commentators' names are self-assigned 'screen names', as they are colloquially known. For the purposes of this research the two are the same, although it may be that an analysis of online pseudonyms could find some correlation between screen names and comment styles.)

Further evidence that anonymity leads to negativity comes from Rowe's (2015) comparison of comments on The Washington Post's website and on its Facebook page. The differences in the two platforms provide an opportunity to compare the relative anonymity of the website to Facebook, "a community where people use their real identities" (p125), at least in theory. Comments on the newspaper's website were found to be less civil than those on its Facebook page, and the incivility in the website comments was much more likely to be directed at other commentators than those on the Facebook page.

Reader's (2012) analysis of essays about anonymity found that the journalists who wrote them used terms like 'gutter', 'trash' and 'crudity' to describe the comments. Hermida and Thurman (2008) explain that right from the earliest days of the move to allow comments on news articles, some senior news executives were looking to abandon or heavily moderate them. Those who oppose the expansion of comment platforms argued that anonymity seemed to prompt commentators to be more negative than would otherwise be expected.

Negative comments do not only insult or annoy those who read them. Negative comments may cause readers to lose respect for the hosting news outlet as it is responsible for any perceived lack of civility (Reich 2011). Negative comments can also affect readers' perceptions about the news they read. Anderson et al.'s (2014) experimental study found that readers of articles featuring negative comments strengthened their opinions about the topic at hand, while readers of civil comments on the same article maintained more open attitudes.

While news executives and some readers may not favour comments at all due to the prevalence of negative comments caused by spontaneity and anonymity, commentators themselves have been found to laud anonymity. It is doubtful that many would admit to wanting to produce hateful, hurtful comments; instead they argue (Reader 2012) that anonymity is supposedly the only way that private individuals can speak truth to power and resist the dominant ideological position of the media. To use the language of Hall's (2006) 'encoding / decoding' theory, some commentators argue that they can only take an oppositional decoding position to supposedly dominant ideologies if they are able to do so without being identified.

Over time, those who track news outlets' comment systems will notice that their availability may disappear due to the on-going controversies over maintaining them, only to reappear, albeit sometimes in reduced form. The Mail Online's system allows anonymous, unmoderated commenting with upvoting and downvoting on almost all articles, something that is disappearing on other websites. Elsewhere, controversial topics are not open to comments, moderators approve comments before they 
appear, and downvoting is sometimes not allowed, presumably to prevent posts from being mass downvoted as expressions of disapproval.

The reason for the removal of comment systems is explained by previous research that has framed the analysis of comments in terms of 'politeness' versus 'impoliteness' or 'civility' versus 'incivility'. Neurauter-Kessels (2011), for example, discusses comments in terms of 'politeness' and 'impoliteness', arguing that impoliteness can be used strategically by commentators to attack the credibility and authority of the journalist authors of articles being commented on. Facial expressions, gestures and prosodic features are unavailable to comment writers. Less-nuanced written approximations - emoji, emoticons, and pseudo-transcription notations such as bold text for shouting - are weak in that they may be either misinterpreted or completely uninterpretable to those who are unfamiliar with them. Thus, commentators have to use clearly impolite language to show disrespect to the journalists they are criticising.

Most research on comments prefers the 'civility' versus 'incivility' distinction (Anderson et al. 2014; Blom et al. (2014); Papacharissi 2004; Reader 2012; Rowe 2015). Papacharissi (2004) defines 'civility' as "positive collective face; that is, deference to the social and democratic identity of an individual" (p267), while 'incivility' is "vitriolic and rancorous" (Reader 2012, p506). Papacharissi (2004) in fact distinguishes between 'polite' and 'civil', arguing that they should not be used synonymously. 'Civil', for her, should denote the promotion of civil (ised) society, so one could be civil while being impolite. Following this definition, she argues that comments on political discussion groups were more civil than might be expected.

However, most research on comment civility / incivility does not include the specific mention of democratic identity, focusing instead on incivility as harm by a language producer to the social identity of the receiver. Blom et al. (2014 p1318), for example, do not define 'civil' explicitly, but we can understand their operational definition by seeing that they coded incivil comments as those that "humiliate" or "threaten" others. More frequent commentators in their research were found to be less civil than infrequent commentators, but the voting patterns related to their comments was not assessed in the research, so we know only that comment frequency correlated with incivility, but nothing about their popularity.

However, these researchers analysed comments that were directed at the journalists who wrote the articles being commented on, the media outlet responsible for the article, or other commentators on those articles. In the data I examine, top comments on Mail Online news articles, no comment was directed at commentators, journalists or the media platforms themselves. Instead, comments were directed at specific participants in the articles, specific targets who were not directly mentioned in the articles, or at society generally. I thus use the term 'negative' to highlight this pessimism in comment content, and also to distinguish the nature of the comments I examine from those in other research.

Despite the time and labour involved in maintaining comments sections, especially when publishers sometimes do not see their value (Reader 2012), they are kept open on some news platforms. Readers expect to be able to comment anonymously, which they suggest allows for honest expression of opinion, and they sometimes prefer comments sections to the articles. "Straight to the comments" is often the top comment on articles that promise to have lively or controversial comments sections, leading readers to claim to have skipped the article itself. For example, "(+17,263 / -328) Straight to the comments...", in an article about the Duchess of Sussex Meghan Markle's fashion choices. In addition to satisfying readers' desire to comment for whatever reason, keeping comment sections open wards off accusations that the news outlet has something to hide. Reich (2011) explains that some commentators say news outlets and specific articles that do not allow comments are viewed suspiciously and accused of pre-emptively censoring those who want to present oppositional positions.

\section{Methodology}

The data is drawn from Mail Online articles posted in the news section. Guided by Neurater-Kessels' (2011) analysis, which gathered comments over a period of five days, the top comments on articles over a one-week period from August 30, 2018, to September 5, 2018, were examined.

The comments were gathered six weeks after the articles were first published, by which time the comments for the articles had closed. The dataset is limited to articles written by Mail Online staff, as 
commenting is disabled on articles written by press association journalists. To ensure that the comments were both popular by upvote count and popular in relation to downvotes, only top comments that had more than one thousand upvotes and a minimum 2:1 ratio of upvotes to downvotes were recorded. This led to a corpus of 65 top comments spread over approximately 2,000 words. The most popular top comment had 14,356 upvotes and a 70:1 upvote/downvote ratio. The least-most popular comment had 1,006 upvotes and a 20:1 upvote/downvote ratio.

Online comments of this type are particularly productive for the study of style as comment writers are unlikely to have had any previous explicit instruction on how to write comments. Instead, they must must induce the specific stylistic features of those comments they read, then apply their knowledge to comments that they write. The one thousand minimum number of upvotes ensures that each comment is popular, which provides some evidence that voters approve of the content, its stylistic realisation, or both. (It is beyond the scope of this paper to provide statistical support for my claim that one thousand upvotes is a high number, but it seems that fewer than one in ten articles with comments reaches this number of upvotes.) Next, high numbers of upvotes and downvotes signal greater reader engagement with the comment. Finally, both the commentators and the voters are unaware of the researcher's presence, so we can guess that Labov's (1972) 'observer's paradox' is not relevant to the writing and voting process.

The top comments were analysed using the tools of critical discourse analysis (CDA), tools which Fairclough (1995) argues are useful for examining the ideological struggle that exists in language use. CDA research is focused on revealing the relationship between language and power (Widdowson, 2004), and the use of language to resist impositions of power (van Dijk, 2003). For the CDA analyst, "any aspect of linguistic structure, whether phonological, syntactic, lexical, semantic, pragmatic or textual, can carry ideological significance" Fowler (1991 p67). Hakam (2009) has argued that media discourse is a notably salient source of data for CDA analyses, as it is the mass media that transmit and maintain ideologies. Comment sections present their users with the opportunity to challenge media ideologies, as they can comment in order to "subvert the intended effects of central messages by juxtaposing contradictory sentiments of other users alongside of the central messages that a persuasive source intends to convey" (Walther et al. 2010 p469). The authority of a traditional news source is often opposed by the co-presence of comments, which gives readers and analysts the occasion to see how commentators resist dominant news narratives and to see how popular attempts to re-frame such narratives are with voters.

The comments were coded for negativity if they, either explicitly or implicitly, made negative evaluations of participants in the news articles, the articles' authors, or other commentators. Only one top comment, praise for Britain's National Health Service, was found to be unequivocally positive. One top comment was critical of the Mail Online, echoing the purpose Neurauter-Kessels (2011) outlined in her research.

The remaining 63 comments made negative evaluations of a human participant in the article (Comment 1 below, referring to British Prime Minister Theresa May's dancing), a non-human participant (Comment 2 below, referring to London), or of a superordinate of a participant (Comment 3 below, in which the specific subordinate Twitter, the social media platform named in the article, is subsumed into the general superordinate 'social media'.) The number of upvotes and downvotes follows the excerpt.

Comment 1 "So embarrassing. For God's sake stop it woman." (+2089/-371)

Comment 2 "Can't blame him for wanting to move away from that hell hole!" (+3091/-45)

Comment 3 "Social media is destroying us." (+1006/-47)

With regards to analysing the stylistic features of the comments, they were first analysed in terms of how they displayed their writers' stance, that is, "the speaker's or writer's feeling, attitude, perspective, or position as enacted in the discourse" (Strauss \& Feiz 2014, p275). Manipulating modality is one means of showing one's stance. For example, a lecturer who uses little epistemic modality with students portrays herself or himself as confident, while the appearance of epistemic modality in the same person's interactions with colleagues suggests an openness to discussion. Thompson (2014) suggests that modality exists on a continuum running from 'high' to 'median' to 'low'. The co-text and context of the modality being examined help us make the determination as to 
where it exists on this continuum, but there is no way to categorise each discretely into absolute categories.

Modality can be 'epistemic', meaning that the truth value of the proposition is shifted ('She should be there.' versus 'She must be there.') or 'deontic', meaning the level of obligation being suggested is shifted ('You should go.' versus 'You must go.'), but there is no deontic modality in the data. Epistemic and deontic modality are respectively known as 'modalization' and 'modulation' (Thompson 2014) in some discussions, but I prefer what I think is the more common term. Modality can be realised in through various linguistic expressions - modal verbs in the finite position of the verb group ("They should be there."), mood adjuncts ("They are usually there.") and interpersonal grammatical metaphors ("I think they are there.") - but as modal verbs are the only type that appear more than once I ignore the others here.

Guided by Chapman's (2016) discussion of the relationship between pragmatics and stylistics, the research focused then on the pragmatic analysis of comments in an effort to see how commentators use implicature (Grice 1975) to create meanings different than those that their words alone would signify. As Chapman (2016) explains, stylistic analyses using pragmatics are productive as they allow us to explain with some precision the difference between what was written and what was meant, rather than relying on impressionistic explanations that we 'just know' someone meant something other than what she or he wrote. This is what Davies (2007) calls the difference between 'sentencemeaning' and 'speaker-meaning' ('writer-meaning', in the case of online comments), so an analysis of pragmatics requires "the need for a logical explanation of the gap between the words and the speakerintention” (p2322).

This research is not a quantitative analysis, so no claim is made that the results here predict other top comments. However, as explained above, comment sections are generally found to be negative ('impolite' and 'incivil', in the words of other researchers) in their overall tone, so there is no reason to expect that other news outlets comment sections would be different. Rather, this is one of Weick's (1989) 'thought trials' that may provide insight into directions for future research. Mahlberg (2010) explains that corpora are advantageous for stylistic analysis as they allow robust description of common features in genres of text (although the interpretation of the effects is still reliant on the analyst). With the recent release of Simon Fraser University's Opinion and online comments corpus (Kolhatkar et al. 2018), we can expect to see an increase in the amount of research in this area.

Commenting on Mail Online articles requires users to register, but they need only provide an email address and choose a screen name. No identifying details are needed to register, so users are anonymous in relation to their offline selves. In addition, the purpose of the research is to identify salient features of the comments, not to criticise their authors for writing them. However, as Spilioti and Tagg (2016) explain, commentators' perceptions of what is public and what is private may differ from the definitions of those platforms they comment on. Commentators presumably know that their comments are publicly visible and agree to such by registering to comment, but they may not consent to having their screen names used in research, so I have removed them from all comments.

\section{Results - Stylistic Features in Negative OnLine Comments}

This section presents the three most common stylistic features used to make negative evaluations that were uncovered during the analysis. The most common method is the use of relational processes (Halliday and Matthiessen 2014), which are primarily realised through the verb 'be' in any of its tense and aspect combination. The verb has no meaning in such processes, instead functioning to link a 'carrier', the subject of the verb, with an 'attribute', a description of that carrier placed in the subject complement position. In the following exemplar comments, we see attributive relational processes with the carrier italicised, the head word of the attribute in parentheses and the entire attribute group underlined.

Comment 4 "Khan is (complicit) to the violence through failure to act" $(+1552 /-90)$

Comment 5 "she's mentally (unhinged)" (+3908/-28)

Comment 6 "This is sickeningly sociopathic (behavior)!" (+8347/-286)

In Comment 4 the mayor of London, Sadiq Khan, is accused of being involved in a rise in crime during his on-going tenure. In Comment 5 a claim is made about actress Roxanne Pallet's behaviour 
on a television reality show, Celebrity Big Brother. In Comment 6 the subject pronoun 'this' refers to entrepreneur Elon Musk accusing someone of being a paedophile. None of these three claims is made by the authors or interviewees in the news articles themselves, so the commentators are not simply repeating what they read. Rather, the commentators are producing 'formulations' (Nofsinger 1991), linguistic moves that show they are aligned to the discourse by being able to summarise what was said or written. (A parent who asks an apparently-uninterested child "What did I just say?" is demanding that the child show such alignment by repeating or formulating the parent's turn.)

Formulations for the articles discussed by commentators in Comments 4, 5 and 6 could have been realised as positive evaluations, such as "Khan is a good mayor..." and so on. Instead, we see two attributes in which the head word itself is negative, 'complicit' typically denotes involvement in immoral or illegal acts and 'unhinged' metaphorically denotes mental derangement, and the rest of the phrase contribute to the negative evaluation. In the case of "behavior", which has neither positive or negative connotations, the modifiers "sickeningly sociopathic" make it clear that this is a negative evaluation, one that other readers approve of, as indicated for this comment and others by the significant number of upvotes in relation to the number of downvotes. Evaluations in this data are mostly realised with high epistemic modality or absolutely, that is, with no modality to shift the propositions to "the region of uncertainty that lies between 'yes' and "no"" (Halliday and Matthiessen 2014 p176). Two-thirds of the comments (43 out of 65) analysed feature no modality. In these, the authors present their comments without any attempt to hedge the negative propositions they make. It may seem odd to base a claim on the absence of certain linguistic forms, but as Huckin et al. (2012) argue, in critical discourse analytic research it is important to think about what could have been said, but was not, especially with regards to linguistic forms that are available to all proficient users of a language. The absence of modality realised through modal verbs indicates a style that favours absolute grammatical realisation of verbs over modalised forms.

There are 36 modal verbs used across the remaining 22 comments. These include will, would, must, may, should, can, can't, cannot, could and couldn't. One modal was deontic ("Brexit should mean..."), and nine were conditional using the word 'would' which indicated that the proposition is currently counter-factual. The remaining 26 modals, examples of which are seen below, are at the high end of the continuum for epistemic certainty.

Comment 7 "Don the Con, will never change." (+843/-370)

Comment 8 "He knows the average person can't afford a protracted legal battle against a billionaire" $(+8347 /-286)$

Comment 9 "We know, the criminals will know, we can't protect our homes (so criminals are not worried)" (+3058/-21)

Any of the modal verbs which I have italicised above could, for example, be replaced with a form of 'may' to indicate median or low modality: 'may never change', 'may not afford', and so on. As Butt et al. (2000) explain, it is sometimes difficult to distinguish between the use of 'will' for high epistemic modality and for future. Using 'may' in place of 'will' in Comments 7 or 9 clarifies that these 'will' tokens are epistemic. Of course 'will' refers to a future action or state; American President Donald Trump ("Don the Con" in Comment 7) cannot change his behaviour in the past, and any immediate present change will only be apparent in the future, but the modal 'will' is here to show the commentator's firm stance with regards to the epistemic possibility of such a change occurring at any time.

The frequency of use or non-use of modality can be seen as an expression of equality or authority on the part of the writer or speaker. The absence of modality in most of the comments that were analysed, and the presence of only high epistemic modal verbs in others, suggests that in this situation those who present their opinions with authority accrue more upvotes.

Other top comments do not follow the relatively simple carrier + relational process + attribute structure to make directly negative propositions. Instead, in 24 of the top comments the commentators rely on readers to interpret comments as meaning more than what is written, as in the comments below.

Comment 10 "No one would notice if an MP went on strike" (+670/-7)

Comment 11 "Pay your full taxes like the rest of us!" $(+14356 /-192)$ 
Comment 12 "There really is wonderful people out there. An absolute diamond and credit to her parents." (+4341/-37)

The implicatures in these examples rely on readers carrying some of the cognitive load in their interpretation, making them more reader-centred than Comments 1 through 9. For Comments 10, 11 and 12, readers must follow the process of decoding explained by Davies (2007): first, judge if they have an appropriate conventional meaning in relation to the article being commented on; and second, if not, look for a most useful, implicated meaning. For Comment 10, we can assume that readers take a mental journey along these lines: when people work there is some recognisable effect; a strike involves the deliberate avoidance of work; avoidance of work leads to the effect not occurring; if no one notices the effect not occurring during a strike then nothing has changed; therefore, MPs' work does not create a recognisable effect.

Comment 11 refers to an article that discusses "celebrity tax avoiders". The text uses language including "tax avoidance schemes", "a scheme challenged by HMRC [the United Kingdom's government department for tax collection]" and "sheltered", all of which suggest that those named are finding ways of reducing their tax payments. However, the article does not claim that anyone involved has not paid their required taxes. The one mention of possible criminal behaviour, "a prosecution for tax evasion in 1989", does not mention that the case ended in an acquittal.

The summary of the article is thus that some celebrities are reducing their tax payments through legal means. "Pay your full taxes like the rest of us!" makes two separate claims. First, that those being addressed, the celebrities named in the article, do not pay their full taxes, although the article never suggests that they do not, and second, that "the rest of us" do pay our taxes, but no data exists to support this claim. The implicature here is generated by the words 'full' and 'us', in that not enough has been written to explain what the commentator means by these words. As is common to implicatures, we cannot determine precisely which words the author left out.If we assume negotiation between the writer and readers, as Grice has explained, we can interpret that by 'full' the writer meant 'the amount you owe before relying on tax reduction techniques named in this article' and by 'us' something akin to 'those who read this, who are not celebrities'. The votes in favour of this comment suggest that readers interpret the implicature in this way or in a similar manner, and want to signal that it is true.

Comment 12, a comment that is at first reading positive, also generates an implicature. The article is about a woman who found $£ 1,000$ then returned it to the person who lost it. The text of the article itself is about one specific woman, while the first sentence of the comment appears to flout the maxim of quantity by referring to "people" instead of just to that individual. In addition, readers will understand that the sentence beginning with "An absolute diamond..." is an example of "wonderful people" by realising that the maxim of relation, while flouted, provides the link between the two. This, supported by the inclusion of an emphatic "really", allows us to interpret this as meaning that the individual is not representative of other "people out there", who are therefore not "wonderful". It is beyond the scope of this research to go into detail about second-order comments that respond to Comment 12, but other positively-rated comments in the thread such as "I wish there was more people like her." and "How many others would have done the same thing..?? Not too many I am guessing...." suggest that this pessimistic interpretation of the implicature is likely correct. 5. DISCUSSION AND CONCLUSIONS

This research argues that three common stylistic features of comments at the Mail Online are the use of carrier + relational verb + attribute structures, the realisation of high epistemic modality, and the generation of implicatures. Reagle (2015) identified generic features of comments, but did not provide any distinctions between different comment platforms. My analysis suggests that further distinction between comments on various platforms is productive as it may prompt consideration of how different comment types are used for different purposes. Impolite comments on British broadsheet newspaper websites are used to attack the authority of those newspapers' journalists (NeurauterKessels 2011). Incivil comments on The Washington Post's Facebook page were found to be directed at other commentators (Rowe 2015). The sometimes less confrontational nature of comments on Facebook might signal a desire for conviviality (Tagg et al. 2017).

It is not unknown for groups of commentators on online newspapers to develop different practices, even when the newspapers themselves are similar. Canter (2013 p608) found that the comments 
sections on two British local newspapers were distinct in that comments on one were "more abusive" and "more extreme" than the other, which suggests that commentator communities develop in distinct ways.

At the Mail Online, the presence of some common stylistic features in top-rated comments suggests that commentators see what is popular in existing top comments, then make comments that will be similarly popular. My theoretical assumption is that those who comment wish to engage in 'taskcontinuative' behaviour (Bergvall \& Remlinger 1996) that shows their identities as proficient group members by posting their comments in order to see others react to those comments. Presumably, up voted comments are seen as successful, leading to a validated online identity as a Mail Online commentator. ('Task-divergent' behaviour such as posting advertisements, making comments unrelated to the topic at hand, etc., are ignored here.) We cannot measure any innate sense of satisfaction that commentators may receive from commenting, so up votes and downvotes are the only means of measuring whether or not a comment is successful with the online community.

The concept of 'community of practice' is defined by Eckert and McConnell-Ginet (1992 p464) as "an aggregate of people who come together around mutual engagement in an endeavor". Wenger's (1998) argument for the significance of communities of practice in the analysis of language use says that such communities must include three essential features: mutual engagement, joint enterprise and a shared repertoire. First, 'mutual engagement' refers to the presence of interaction between community members, which is true of Mail Online commentators who post, reply to others' comments, and vote on them. Whether they upvote or downvote is not relevant, either action shows participation in the community. As Reagle (2015) explains, the popularity of online comments is partly due to the ability of members to react by voting, then to see how their votes align with others' votes. Second, the 'joint enterprise' of the Mail Online comment community seems to be to re-frame news reports to challenge the discourse of the newspaper. Top-rated comments with significant numbers of votes can challenge media representations of events (Walther et al. 2010). An article about crime in London can be made worse by libeling the mayor, or an optimistic article about a woman returning found money can be pessimistically re-framed as atypical behaviour in British society. Third, members of a community of practice have a 'shared repertoire' of stylistic forms that they use to signal membership. The forms need not be unique to the group, but the use of the aggregate of forms, which I argue include those described earlier, help distinguish 'core' (Wenger, 1998) members from new members and non-members.

Significantly, Eckert and McConnell-Ginet (1992 p464) explain that "shared ways of talking" and "values" characterise members of a community of practice. New members of the community, consciously or not, take on the language of established members and tend to express the community's shared values by using that language. Membership is thus claimed by the use of previouslyestablished linguistic features of the community of practice. A stylistic analysis, such as that presented in this research, allows us to see which features have been used, and suggests that the effect of their use, a primary concern of stylistics (Coupland 2007), can be measured by the number of upvotes that successful comments receive. Walther et al. (2010) argue that online communities are not different from face-to-face communities in terms of how in-group influence is created and maintained, writing that "when individuals identify with peers who are visually anonymous and with whom they do not directly interact, they should be susceptible to social influence from that group" (p469). The identification of shared linguistic forms in online communities, which are potentially limitless in size, is thus an indication of shared values, which has significant implications for the transmission of ideas through wide-reaching networks of like-minded individuals. Further research in this area should focus on establishing how community membership is signalled, if at all, in positive comments, which could provide additional evidence for the existence of common stylistic features in the written language of communities of practice.

Funding: This research received no external funding.

Conflicts of Interest: The author declares no conflict of interest.

\section{REFERENCES}

[1] Anderson, A., Brossard, D., Scheufele, D., Xenos, M., \&Ladwig, P. 2014. The "nasty effect:" Online incivility and risk perceptions of emerging technologies. Journal of Computer-Mediated Communication 19: 373-387. 
[2] Bergvall, V., \& Remlinger, K. 1996. Reproduction, resistance and gender in educational discourse: The role of critical discourse analysis. Discourse \& Society 7: 453-479.

[3] Blom, R., Carpenter, S., Bowe, B., \& Lange, R. 2014. Frequent contributors within U.S. newspaper comment forums: An examination of their civility and information value. American Behavioral Scientist 58(10): 1314-1328.

[4] Brown, P., \& Levinson, S. 1987. Politeness: Some universals in language usage. Cambridge: Cambridge University Press.

[5] Butt, D., Fahey, R., Feez, S., Spinks, S., \&Yallop, C. 2000. Using functional grammar (2nd ed.). Sydney: Macquarie University.

[6] Canter, L. 2013. The misconception of online comment threads. Journalism Practice 7(5): 604-619.

[7] Chapman, S. 2016. Pragmatics and stylistics. In The Bloomsbury companion to stylistics. Edited by V. Sotirova.

[8] London: Bloomsbury, pp. 78-91.

[9] Coupland, N. 2007. Style: Language variation and identity. Cambridge: Cambridge University Press.

[10] Davies, B. L. 2007. Grice's cooperative principle: Meaning and rationality. Journal of Pragmatics 39: 2308-2331.

[11] Van Dijk, T. 2003. Critical discourse analysis. In The handbook of discourse analysis. Edited by D. Schiffrin, D.

[12] Tannen, \& H. Hamilton. Oxford: Blackwell, pp. 352-371.

[13] Eckert, P., \& McConnell-Ginet, S. (1992). Think practically and look locally: Language and gender as community-based practice. Annual Review of Anthropology 21: 461-490.

[14] Fairclough, N. 1995. Critical discourse analysis: The critical study of language. London: Longman.

[15] Fothergill, J. 2014. Newspaper ABCs: Digital figures for August 2014. Campaign.

[16] Fowler, R. 1991. Language in the news: Discourse and ideology in the press. London: Routledge.

[17] Gardiner, B., Mansfield, M., Anderson, I., Holder, J., Louter, D., \&Ulamnu, M. 2016. The dark side of Guardian comments. The Guardian. Retrieved August 17, 2017, from https://www.theguardian. com/ technology/2016/apr/12/the-dark- side-of-guardian-comments Georgakopoulou, A., \&Goutsos, D. 1997. Discourse analysis. Edinburgh: Edinburgh University Press.

[18] Grice, P. 1975. Logic and conversation. In Syntax and semantics. Edited by P. Cole \& J Morgan., New York: Academic Press, pp. 41-58.

[19] Hakam, J. 2009. The 'cartoons controversy': A critical discourse analysis of English-language Arab newspaper discourse. Discourse \& Society20: 33-57.

[20] Hall, S. 2006. Encoding/decoding. In Media and cultural studies: Keyworks. Edited by M. Durham \& D. Kellner.

[21] Oxford: Blackwell, pp. 163-173.

[22] Halliday, M., \& Hasan, R. 1976. Cohesion in English. Harlow, Essex: Longman.

[23] Halliday, M., \& Matthiessen, C. 2014. Halliday's introduction to functional grammar (4th ed.). Abingdon, Oxon: Routledge.

[24] Hermida, A., \& Thurman, N. 2008. A clash of cultures. Journalism Practice 2(3): 343-356.

[25] Huckin, T., Andrus, J., \& Clary-Lemon, J. 2012. Critical discourse analysis and rhetoric and communication.

[26] College Composition and Communication 64(1): 107-129.

[27] Kolhatkar, V., Wu, H., Cavasso, L., Francis, E., Shukla, K., \& Taboada, M. 2018. SFU opinion and comments corpus.

[28] Simon Fraser University. Retrieved September 5, 2018, from https://researchdata.sfu.ca/islandora/ object/islandora\%3A9109

[29] Labov, W. 1972. Sociolinguistic patterns. Oxford: Blackwell. Lambrou, M., \& Durant, A. 2014. Media stylistics. In The Cambridge handbook of stylistics. Edited by P. Stockwell \& S. Whiteley. Cambridge: Cambridge University Press, pp. 503-519.

[30] Lave, J., \& Wenger, E. 1991. Situated learning: Legitimate peripheral participation. Cambridge: Cambridge University Press.

[31] Mahlberg, M. 2010. A corpus stylistic perspective on Dickens' Great Expectations. In Contemporary stylistics.

[32] Edited by M.Lambrou \& P. Stockwell. London: Continuum, pp.19-31.

[33] Neurauter-Kessels, M. 2011. Im/polite reader responses on British online news sites. Journal of Politeness Research 7(2): 187-214. 
[34] Nofsinger, R. 1991. Everyday conversations. Prospect Heights, Illinois: Waveland Press.

[35] OED Online. 2018. negative. Retrieved 17 October 2018.

[36] Palmer, F. 2001. Mood and modality (2nd ed.). Cambridge: Cambridge University Press.

[37] Papacharissi, Z. 2004. Democracy online: Civility, politeness, and the democratic potential of online political discussion groups. New Media \& Society 6(2): 259-283.

[38] Rampton, B. 2002. Styling the other: Introduction. Journal of Sociolinguistics 3(4): 421-427.

[39] Reader, B. 2012. Free press vs. free speech? The rhetoric of "civility" in regard to anonymous online comments.

[40] Journalism \& Mass Communication Quarterly 89(3): 495-513.

[41] Reagle, J. 2015. Reading the Comments: Likers, Haters, and Manipulators at the Bottom of the Web. Cambridge: MIT Press.

[42] Reich, Z. 2011. User Comments: The Transformation of the Participatory Space. In Participatory journalism: Guarding gates at online newspapers. Edited by A. Hermida, D. Domingo, A. Heinonen, S. Paulussen, T. Quandt, Z. Reich, \& M. Vujnovic. Hampshire: Palgrave, pp. 96-117.

[43] Rowe, I. 2015. Civility 2.0: A comparative analysis of incivility in online political discussion. Information, Communication \& Society18(2): 121-138.

[44] Santana, A. 2011. Online readers' comments represent a new opinion pipeline. Newspaper Research Journal 32(3):66-81.

[45] Spilioti, T., \& Tagg, C. 2016. The ethics of online research methods in applied linguistics: Challenges, opportunities, and directions in ethical decision-making. Applied Linguistics Review 8(2-3): 163-167.

[46] Strauss, S., \& Feiz, P. 2014. Discourse analysis: Putting our worlds into words. London: Routledge.

[47] Swales, J. 1990. Genre analysis: English in academic and research settings. Cambridge: Cambridge University Press.

[48] Tagg, C., Brown, A. A., \&Seargeant, P. 2017. Taking offence on social media: Conviviality and communication on Facebook. London: Palgrave.

[49] Thompson, G. 2014. Introducing functional grammar (3rd ed.). London: Routledge.

[50] Walther, J., DeAndrea, D., Kim, J., \& Anthony, J. 2010. The influence of online comments on perceptions of antimarijuana public service announcements on YouTube. Human Communication Research 36: 469492.

[51] Weick, K. 1989. Theory construction as disciplined imagination. The Academy of Management Review 14(4): 516-531.

[52] Wenger, E. 1998. Communities of practice. Cambridge: Cambridge University Press.

[53] Widdowson, H. 2004. Text, context, pretext. Oxford: Blackwell.

[54] Wright, S., \& Street, J. 2007. Democracy, deliberation and design: The case of online discussion forums. New Media \& Society 9(5): 849-869.

\section{AUTHOR'S BIOGRAPHY}

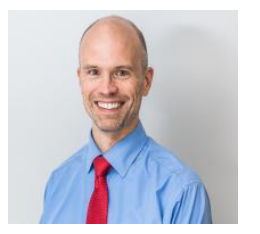

Sean was educated at Carleton University, Canada, and at King's College London, University of London. He is a lecturer at the University of Westminster in London, UK

Citation: Sean Sutherland. Being Negative to be Popular: Style in Online Comments at the Mail Online "International Journal on Studies in English Language and Literature (IJSELL), vol 8, no. 5, 2020, pp. 67-77. doi: http://dx.doi.org/10.20431/2347-3134.0805009.

Copyright: () 2020 Authors. This is an open-access article distributed under the terms of the Creative Commons Attribution License, which permits unrestricted use, distribution, and reproduction in any medium, provided the original author and source are credited. 